\title{
A study of electrode wear ratio on EDM of Ti-6AL-4V with copper-tungsten electrode
}

\author{
Nurezayana Zainal ${ }^{1, *}$, Azlan Mohd Zain ${ }^{1}$ and Safian Sharif ${ }^{2}$ \\ ${ }^{1}$ Soft Computing Research Group, Faculty of Computing, Universiti Teknologi Malaysia, 81310 \\ Skudai, Johor, Malaysia. \\ ${ }^{2}$ Faculty of Mechanical Engineering, UniversitiTeknologi Malaysia, 81310 Skudai, Johor, Malaysia.
}

\begin{abstract}
In this work, a study of electrode wear ratio (EWR) on the diesinking electrical discharge machining (EDM) ofTi-6AL-4V titanium alloy with copper-tungsten $(\mathrm{Cu}-\mathrm{W})$ electrode has been carried out. Pulse on time $(\mathrm{ON})$, pulse of time $(\mathrm{OFF})$, peak current $(\mathrm{V})$ and servo voltage $(\mathrm{SV})$ were seen as the machining parameters. The experiments were run according to the design of experiments (DOE), which is two levels of full factorial with added centre points. The experimental results reveal that pulse on time and peak current are statistically significant parameters for affecting EWR with the p-value of 0.0013 and 0.0012 respectively. Moreover, based on ANOVA, we recognized peak current as the most significant parameters which contribute $31.75 \%$, followed by pulse on time, servo voltage and pulse on time which contribute $30.99 \%, 8.68 \%$ and $0.72 \%$, respectively.
\end{abstract}

\section{Introduction}

Machining process can be determined as the cognitive operation of shaping the workpiece as desired and it is commonly done using machine and cutting tools [1]. In the early 20th century, the machining process is recognized as non conventional machining process which includes milling, bending, grinding, drilling and drilling. Since the coming of novel technologies, there has been modern machining process such as electrochemical machining $(\mathrm{ECM})$, electrical discharge machining (EDM), abrasive water jet (AWJ) and ultrasonic machining (USM) [2, 3, 4].

Electrical discharge machining (EDM) is unitary of the well known modern machining process used in machining materials that are mainly hard to be machined. EDM is widely being used in innovative manufacturing industry purposely used to transfer material from the work piece by controlling erosion through ${ }^{\S}$ a series of electric sparks occurring between the electrode and the work piece immersed in dielectric fluid [5, 6]. Generally, EDM produces complex shapes and permits high precision machining of any strong, difficult-tomachine, breakable or thin materials [7]. In addition, EDM is used for completing parts for aerospace and automotive industry and surgical components [8].

\footnotetext{
* Corressponding author: ezayana@gmail.com
} 
In late years, titanium has become an important material which has widely applied in the aerospace industries. Basically, titanium has a high melting temperature and low thermal conductivity where it belongs, to the group of difficult-to-cut materials which is not suited for traditional machining [9]. Moreover, titanium has a low modulus of elasticity which causes significant spring back after deformation under the cutting load [10]. Hence, EDM process can effectively machine titanium alloy.

Copper-tungsten electrodes provide better surface finish and longer life than the graphite electrodes [7]. The thermal properties of copper-tungsten alloy render it suitable for utilization as an EDM electrode in this field. More often than not, the low melting point of $\mathrm{Cu}$ component reduces the resistance to electrode wear. Moreover, there is porosity in liquid phase sintered electrode due to the insolubility between $\mathrm{Cu}$ and $\mathrm{W}$ due to its high tungsten content [11]. In addition, $\mathrm{Cu}-\mathrm{W}$ electrode has a good wear resistance properties and good thermal conductivity [12]. Therefore, it is desirable for the machining of small holes with flat beds, where high-precision machining is the primary consideration.

In the present study, the effect of different machining parameters (pulse of time, pulse of time, peak current and servo voltage) towards electrode wear ratio (EWR) of Ti-6AI-4V titanium alloy with copper-tungsten electrode is studied. Then, the result of these machining parameters on EWR is analyses using analysis of variation (ANOVA).

\section{Experimental Procedure}

The experimental study was conducted with an objective to identify the machining parameters that significantly affect the EWR. The experiments are carried out utilizing a numerical control programming, electrical discharge machine known as AG40L Sodick. The EDM has the provisions of movement in three axes which are longitudinal (X-axis), lateral (Y-axis) and vertical (Z0-axis). In this effort, titanium alloy Ti-6AL-4V was selected as the work piece and copper-tungsten $(\mathrm{Cu}-\mathrm{W})$ electrode was used for machining the work piece. The diemeter of the electrode is $8 \mathrm{~mm}$. Then, the dielectric fluid used is oil. The specimens were EDMed at $1.5 \mathrm{~mm}$ depth of hole. Figure 1 illustrates the machining setup of EDM process. Table 1 presents the design factors and their levels.

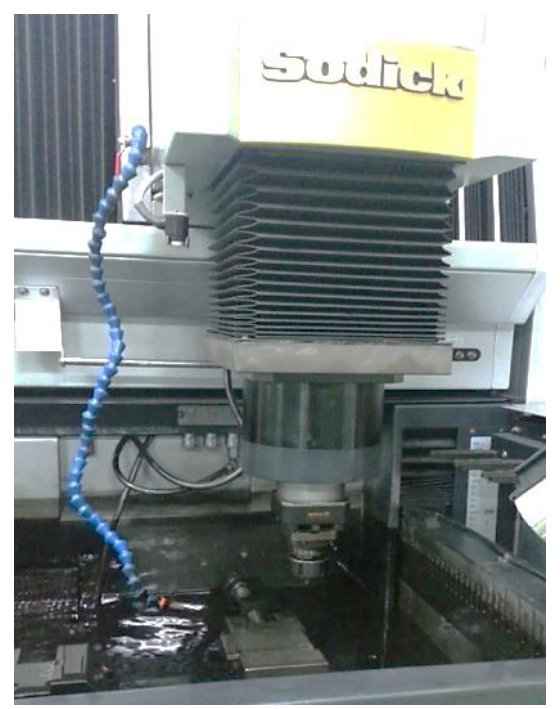

Fig. 1. Experimental setup of electrical discharge machining. 
Table 1. Factor and level for EDM parameters of titanium alloy.

\begin{tabular}{|l|l|l|l|l|}
\hline Symbol & Name & \multirow{2}{*}{ Units } & Level & \\
\cline { 4 - 5 } & & & Low (-1) & High (+1) \\
\hline ON & Pulse on time & $\mu \mathrm{s}$ & 150 & 230 \\
\hline OFF & Pulse off time & $\mu \mathrm{s}$ & 60 & 90 \\
\hline IP & Peak current & Ampere & 10 & 12 \\
\hline SV & Servo voltage & Volt & 30 & 60 \\
\hline
\end{tabular}

Two levels of full factorial design with added center points were used to carry out a total number of 20 experiments. In this study, EWR is defined as the ratio of the volume of material removed from the electrode to the volume of material removed from a workpiece. A digital balance (Ohaus - PA 214) was utilized to quantify the weight of the electrodes and work piece required. EWR was calculated by the formula as expressed in (1) and (2):

$$
E W R=\frac{\text { volume of material removed from electrode }}{\text { volume of material removed from work piece }} \times 100 \%
$$

$$
E W R=\frac{E_{W B}-E_{W A}}{W P_{W B}-W P_{W A}} \times 100 \%
$$

where, $\mathrm{E}_{\mathrm{WB}}$ is the volume of the electrode before machining $(\mathrm{g}), \mathrm{E}_{\mathrm{WA}}$ is the volume of electrode after machining $(\mathrm{g}), \mathrm{WP}_{\mathrm{WB}}$ is the volume of electrode before machining $(\mathrm{g})$ and $\mathrm{WP}_{\mathrm{WA}}$ is the volume of electrode after machining $(\mathrm{g})$.

\section{Result and Discussion}

The effect of each machining process; pulse on time, pulse off time, peak current and servo voltage on electrode wear ratio (EWR) in EDM of Ti-6AI-4L titanium alloy is discussed in this section. The results for the experiments are further analyzed using analysis of variance (ANOVA) for identifying the significant factors affecting EWR. Design Expert software was employed to carry out the ANOVA approach. Moreover, the electrodes after EDM process can be viewed in Figure 2.

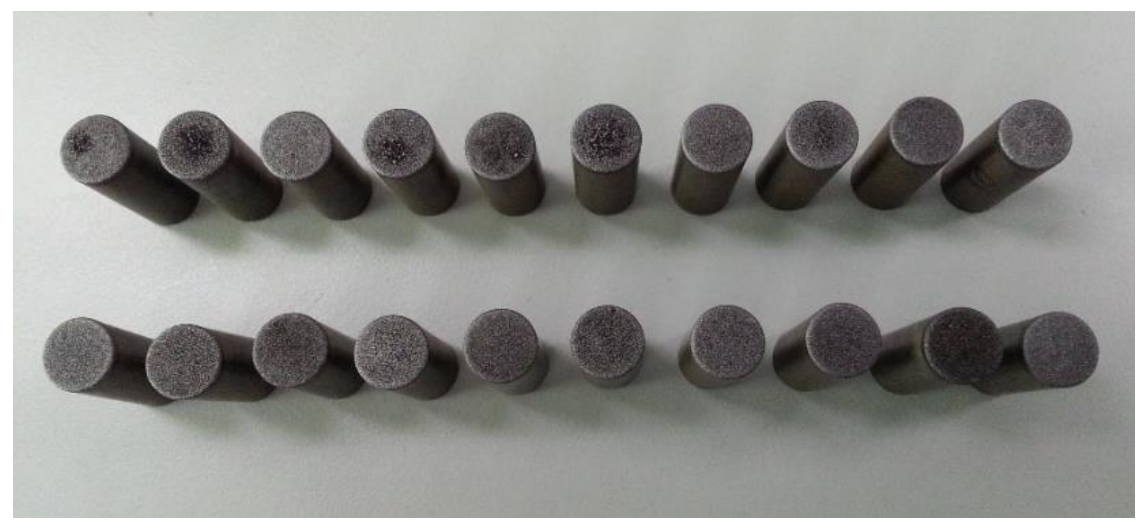

Fig. 2. The electrodes after EDM process. 
From the experimental results plotted in Figure3, it can be seen that run No. 14 gave the highest reduction of EWR during the EDM process (50.04\%). On the other hand, run No. 2 gave the lowest reduction of EWR, which is $16.19 \%$. Moreover, Figure 4 illustrates the effect of different machining parameters on EWR. Figure 4 (c) and Figure 4 (d) show that EWR increases as peak current and servo voltage increases. It can be concluded that high current and high servo voltage results in high EWR. This is imputable to the fact that the higher current will generate a stronger spark which producing more rate of heat energy. Furthermore, Figure 4 (b) shows that EWR increases sharply after the decrement of pulse off time. However, as can be seen from Figure 4 (a), EWR decreases as pulse on time increases from $150 \mu \mathrm{s}$ to $230 \mu \mathrm{s}$.

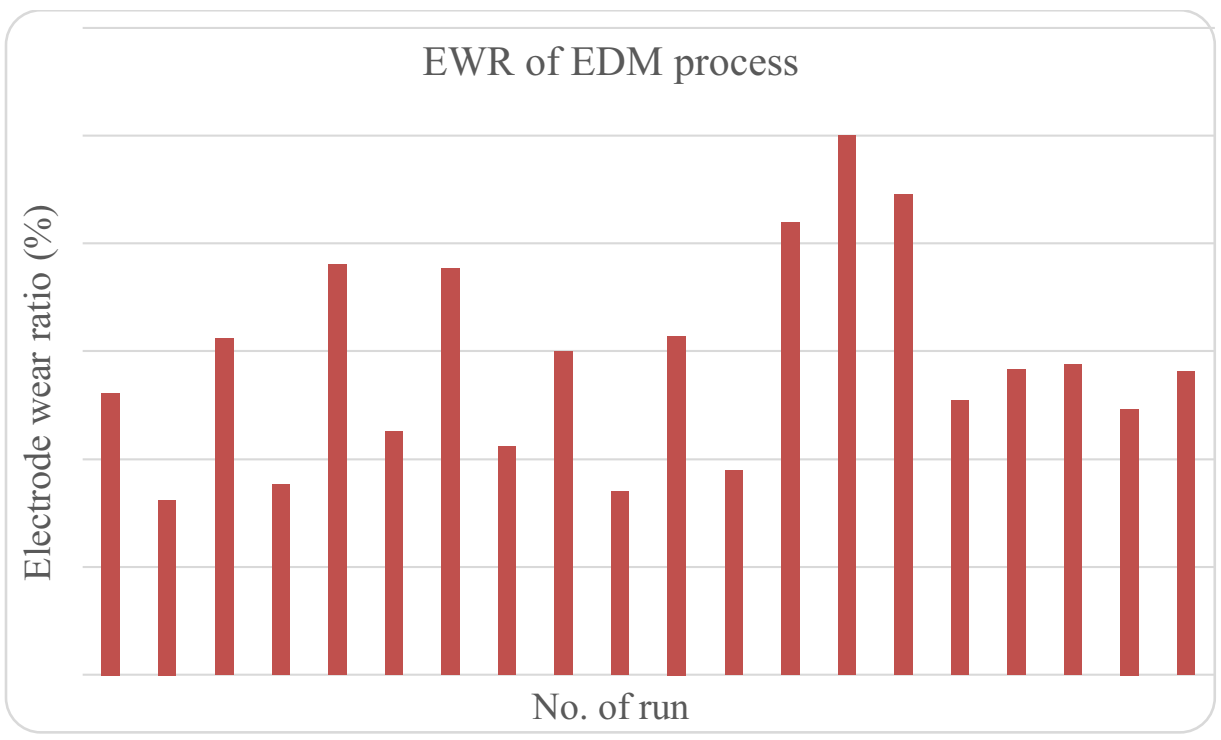

Fig. 3. Analysis of EWR.

Than, the experimental results obtained are evaluated by using analysis of variance (ANOVA) approach. The results of experimental data from ANOVA are given in Table3. This analysis is carried out for a significance level of $\alpha=0.05$, for confidence level of $95 \%$. Agreeing to the ANOVA technique, the values of "p-value" less than 0.05 will indicate the machining parameters are statistically significant. While the "p-value" greater than 0.05 will indicate the machining parameters are statistically insignificant. According to Table 3, we can observe that pulse on time and peak current are statistically significant parameters for affecting EWR with the p-value of 0.0013 and 0.0012 respectively. Besides, pulse off time and servo voltage appears as insignificant parameters for affecting EWR. Furthermore, it can be determined that the peak current is the most effective machining parameters with a $31.75 \%$ contribution as presented in Table 3. It is followed by pulse on time with contributions $30.99 \%$. The less affecting machining parameters are pulse off time with contributions $0.72 \%$ only. 


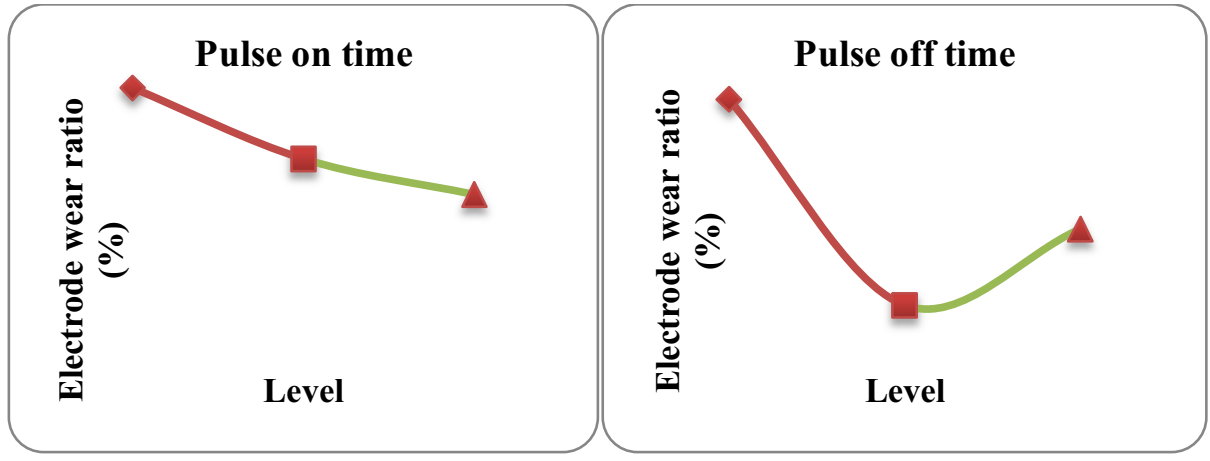

(a)

(b)

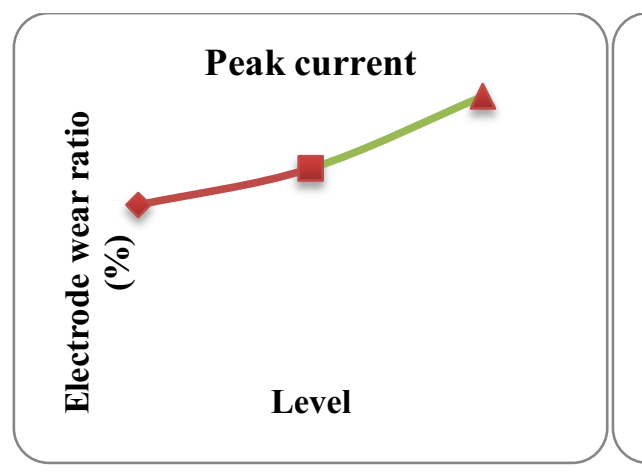

(c)

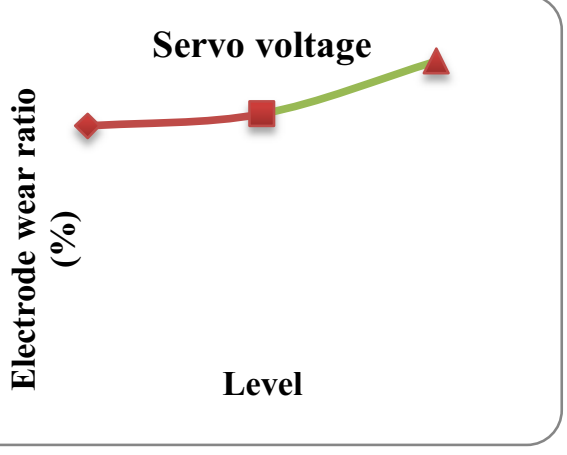

(d)

Fig. 4. Analysis of effect of machining parameters on EWR. (a) Effect of pulse on time on EWR, (b) Effect of pulse off time on EWR, (c) Effect of peak current on EWR and (d) Effect of servo voltage on EWR.

Table 3. ANOVA for EWR.

\begin{tabular}{|l|c|c|c|c|c|c|c|}
\hline Source & $\begin{array}{l}\text { Sum of } \\
\text { square }\end{array}$ & df & $\begin{array}{l}\text { Mean } \\
\text { square }\end{array}$ & f-value & p-value & & $\begin{array}{l}\text { Contribution } \\
(\%)\end{array}$ \\
\hline Model & 0.1228 & 4 & 0.0307 & 9.2898 & 0.0007 & Significant & \\
\hline $\begin{array}{l}\text { A-Pulse on } \\
\text { time }\end{array}$ & 0.0528 & 1 & 0.0528 & 15.9612 & 0.0013 & & 30.99 \\
\hline $\begin{array}{l}\text { B-Pulse off } \\
\text { time }\end{array}$ & 0.0012 & 1 & 0.0012 & 0.3709 & 0.5523 & & 0.72 \\
\hline $\begin{array}{l}\text { C-Peak } \\
\text { current }\end{array}$ & 0.054 & 1 & 0.054 & 16.3563 & 0.0012 & & 31.75 \\
\hline $\begin{array}{l}\text { D-Servo } \\
\text { voltage }\end{array}$ & 0.0148 & 1 & 0.0148 & 4.471 & 0.0529 & & 8.68 \\
\hline $\begin{array}{l}\text { Curvature } \\
0.0012\end{array}$ & 1 & 0.0012 & 0.3494 & 0.5639 & $\begin{array}{c}\text { Not } \\
\text { significant }\end{array}$ & \\
\hline Residual & 0.0463 & 14 & 0.0033 & & & & \\
\hline Lack of Fit & 0.0452 & 11 & 0.0041 & 11.5739 & 0.0340 & Significant & \\
\hline Pure Error & 0.001 & 3 & 0.0004 & & & & 27.86 \\
\hline Cor Total & 0.1702 & 19 & & & & & 100 \\
\hline
\end{tabular}




\section{Conclusion}

The results of EWR of Ti-6AL-4V titanium alloy with copper-tungsten electrode on the different machining parameters have been presented. A higher current accounts for more EWR followed by servo voltage. Initially, pulse off time, minimize EWR from $60 \mu$ s to 75 $\mu \mathrm{s}$, and then its increase the EWR sharply. However, pulse on time account for lower EWR from $150 \mu \mathrm{s}$ to $230 \mu \mathrm{s}$. According to ANOVA technique, we can see that pulse on time and peak current are statistically significant parameters for affecting EWR with the p-value of 0.0013 and 0.0012 respectively. Then, we recognized peak current as the most significant parameters which contribute $31.75 \%$, followed by pulse on time, servo voltage and pulse on time which contribute $30.99 \%, 8.68 \%$ and $0.72 \%$, respectively.

Special appreciation to reviewer(s) for useful advices and comments. The authors greatly acknowledge the Research Management Centre, UTM and Ministry of Higher Education Malaysia (MOHE) for financial support through the Fundamental Research Grant Scheme (FRGS) vot. No. R.J130000.7828.4F721.

\section{References}

1. N. Yusup, A.M. Zain, S.Z.M. Hashim: Procedia Eng., (2012)

2. N. Zainal, A.M. Zain, N.H.M. Radzi, M.R. Othman: J. Intell. Manuf., (2014)

3. A.M. Zain, H. Haron, S. Sharif, Expert Syst. Appl., 37 (2010)

4. A.M. Zain, H. Haron, S. Sharif, Mach. Sci. Technol., 14 (2010)

5. M.B. Ndaliman, A.A. Khan, M.Y. Ali, Int. J. Mech. Mater. Eng.,6, 3 (2011)

6. S. Padhee, N. Nayak, S.K. Panda, P.R. Dhal, S.S. Mahapatra, Sadhana 37, 2 (2012)

7. M.A.R. Khan, M.M. Rahman, K. Kadirgama, Int. J. Adv. Manuf. Tech., 77 (2014)

8. N.M. Abbas, D.G. Solomon, M.F. Bahari, Int. J. Mach. Tool Manu., 47, 7 (2007)

9. S.L. Chen, B.H. Yan, F.Y. Huang: J. Mater. Process. Technol., 87 (1999)

10. B. Kuriachen, J. Mathew, Mater. Manuf. Processes, 30, 8 (2015)

11. L. Li, Y.S. Wong, J.Y.H. Fuh, L. Lu, J. Mater. Process. Technol., 113 (2001)

12. H.T. Lee, F.C. Hsu, T.Y. Tai, Mater. Sci. Eng., 364 (2004) 